\title{
CONSIDERACIONES PARA EL DISEÑO SÍSMICO DE EDIFICIOS ALTOS DE MAMPOSTERÍA CONFINADA UBICADOS EN ZONAS SÍSMICAS
}

\author{
Eric Fernando Espinosa Cazarín ${ }^{(1)}$, Amador Terán Gilmore ${ }^{(2)}$, Oscar Zúñiga Cuevas ${ }^{(3)}$ \\ y Raúl Jean Perilliat ${ }^{(4)}$
}

\begin{abstract}
RESUMEN
Las políticas recientes de fomento a la vivienda en México han buscado optimizar los cada vez más escasos espacios disponibles en las grandes ciudades. Dentro de este contexto, empieza a considerarse cada vez más la construcción de edificios altos. En un edificio alto de mampostería, es muy posible que existan muros con relación de aspecto elevada. Un aumento en la relación de aspecto de un muro resulta en un cambio en su comportamiento ante cargas laterales, lo que lo lleva de una respuesta lateral dominada por corte a una dominada por flexión. Este artículo tiene como objetivo aportar elementos cualitativos y cuantitativos que permiten discutir la posibilidad de construir edificios altos de mampostería confinada en zonas sísmicas. Para ello se diseñó un edificio de 10 pisos ubicado en la Zona de Transición del Distrito Federal, y se llevó a cabo una serie de análisis estáticos no lineales para establecer las propiedades estructurales globales del edificio, y otra de análisis dinámicos no lineales para definir su desempeño sísmico. A partir de los resultados presentados se concluye que es posible construir edificios altos de mampostería en zonas sísmicas, y se identifican algunas de las acciones que deben emprenderse a corto plazo para hacer esto posible.
\end{abstract}

Palabras clave: mampostería confinada; muros esbeltos; daño por flexión; análisis no lineal; desempeño sísmico

Artículo recibido el 10 de septiembre de 2013 y aprobado para su publicación el 21 de julio de 2014. Se aceptarán comentarios y/o discusiones hasta cinco meses después de su publicación.

(1) Ex-estudiante de Posgrado,División de Estudios de Posgrado de la Facultad de Ingeniería, Universidad Nacional Autónoma de México, Circuito Exterior, Ciudad Universitaria, México, D.F., México, C.P. 04510, spinosa_10@ hotmail.com

(2) Profesor,Departamento de Materiales, Universidad Autónoma Metropolitana, Av. San Pablo 180, Col. Reynosa Tamaulipas,México, D.F., México, C.P. 02200. tga@correo.azc.uam.mx

(3) Director General, Soluciones en Ingeniería Estructural y Tecnología, Austria 11 Desp. 6, Col. Centro Urbano, Cuautitlán Izcalli, Estado de México, México, C.P. 54700.ozc@siest.mx, +52(55) 6718-6060

(4) Director General, Jean Ingenieros, Av. Barranca del Muerto 210, Col. Guadalupe Inn, México, D.F., México, C.P. 01020.raul_iois@ prodigy.net.mx 


\title{
CONSIDERATIONS FOR THE DESIGN OF TALL CONFINED MASONRY BUILDINGS LOCATED IN SEISMIC ZONES
}

\begin{abstract}
Recent Mexican policies that promote the construction of housing units are aimed at the optimization of the scarce available spaces in large cities. Within this context, the construction of tall buildings is being considered. Tall masonry buildings will likely have slender walls in their structural system. An increase in the slenderness ratio of a wall results in a change of its behavior when subjected to lateral loads; evolving from a shear dominated response to a bending dominated one. This paper provides qualitative and quantitative elements that allow for a discussion of the possibility of constructing tall confined masonry buildings in seismic zones. To achieve this, a 10-story building located in the Transitional Zone of Mexico City is designed, and a series of static and dynamic nonlinear analyses are carried out to evaluate its global structural properties and seismic performance. From the results of the nonlinear analysis, it is concluded that it is possible to construct tall confined masonry buildings in seismic zones. Actions that need to be undertaken in the short term to make this possible are identified.
\end{abstract}

Keywords: confined masonry; slender walls; damage due to bending; nonlinear analyses; seismic performance

\section{INTRODUCCIÓN}

Las tendencias arquitectónicas y las necesidades de urbanización de los grandes centros de población han dado lugar a edificios de mampostería que exhiben características muy diferentes a las que tenían hace algunos años. Por un lado, es posible ver edificios cuya estructuración no satisface las condiciones de regularidad que se requieren para fomentar un desempeño sísmico adecuado. Por el otro lado, empiezan a construirse edificios que tienen un mayor número de niveles en relación a los que se tenían hace tan solo una o dos décadas. En Ciudad de México es posible observar actualmente varios edificios de mampostería confinada de 5 y 6 pisos; y existe entre la comunidad local de ingeniería estructural, la aspiración de construir edificios más altos. Aunque el Reglamento de Construcciones para el Distrito Federal no limita de manera explícita la altura de las estructuras de mampostería, por el momento los estrictos límites impuestos por las Normas Técnicas Complementarias para el Diseño y Construcción de Estructuras de Mampostería (Gobierno del Distrito Federal, 2004a), NTCDCEM-2004, a la distorsión lateral de diseño restringen de manera importante, desde puntos de vista técnico y económico, el uso de este material estructural en edificios con más de 6 niveles.

Estudios analíticos llevados a cabo en México sugieren una reducción sustancial en la sobrerresistencia que exhiben los edificios de mampostería (en relación a su resistencia lateral de diseño) conforme se incrementa su número de pisos (Valenzuela, 2009). Además, se observó una marcada tendencia de un edificio de mampostería de 6 pisos diseñado conforme a las NTCDCEM-2004, a transitar de manera súbita del estado límite de Seguridad de Vida al de Prevención de Colapso (Terán et al., 2011). En particular, la evaluación de su desempeño sísmico indicó un pequeño margen de seguridad cuando se le sujeta a la acción del sismo para el cual fue diseñado.Bajo estas circunstancias, es importante entender 
que la vulnerabilidad sísmica de un número importante de edificios de mampostería va en aumento, y que la normatividad mexicana fue desarrollada para el diseño y construcción de estructuras de baja altura.

Para hacer posible un desarrollo sustentable de la vivienda en México, es importante estudiar el uso de diferentes materiales estructurales que ofrezcan alternativas atractivas desde puntos de vista económico y ambiental. Una opción que debe estudiarse dentro de este contexto es el uso de mampostería para construir edificios altos en zonas sísmicas, y esto implica la necesidad de desarrollar técnicas de análisis no lineal para este tipo de sistemas con el fin de plantear estudios que hagan posible la formulación de recomendaciones de diseño que no sean excesivamente conservadoras, y que resulten en sistemas estructurales con niveles aceptables de seguridad estructural.

\section{PROPIEDADES ESTRUCTURALES DE MUROS ESBELTOS DE MAMPOSTERÍA}

Cuando un muro alcanza su capacidad de agrietamiento, se desarrollan patrones de grietas y daño que quedan fuertemente relacionados con los elementos mecánicos que dominan su comportamiento lateral. Dependiendo del tipo de mecanismo que desarrolle el muro y de su detallado (que incluye el uso de refuerzo vertical y/o horizontal, y el confinamiento del panel de mampostería por medio de castillos y dalas), este podrá exhibir un comportamiento frágil e inestable que resulte en niveles limitados de deformación inelástica; o un comportamiento dúctil caracterizado por una capacidad de deformación importante y una degradación controlada en presencia de cargas cíclicas. En términos de muros esbeltos de mampostería, es muy importante estudiar cómo lograr que su comportamiento quede dominado por efectos de flexión, y que tipo de detallado hay que proveerles para que tengan la capacidad de desarrollar comportamiento dúctil. Normalmente, cuando se habla de la relación de esbeltez de un muro se hace referencia al cociente entre su altura y espesor. La relación entre la altura y ancho del muro suele denotarse relación de aspecto. Debido a la falta de una mejor terminología, en este artículo el término muro esbelto hace referencia a muros que tiene una relación de aspecto de 2 o mayor.

\section{Modos de comportamiento}

Los resultados experimentales sugieren que los muros de mampostería sujetos a carga lateral tienden a desarrollar tres tipos de comportamiento y daño: A) Flexión; B) Corte; y C) Flexión/Corte. El tipo de comportamiento que desarrolla el muro depende en gran medida de su: A) Relación de aspecto; B) Condición de carga y apoyo; y C) Cuantías de acero vertical y horizontal contenidas en el panel de mampostería y los elementos confinantes.

En general, un muro esbelto de mampostería cuyo comportamiento quede dominado por flexión puede detallarse de tal manera que exhiba un comportamiento dúctil (Priestley y Elder, 1982; Shedid et al., 2009). El daño por flexión debido a cargas laterales en el plano del muro se caracteriza por un patrón de grietas horizontales que desarrolla el mortero ubicado en la parte de tensión, y suele quedar caracterizado por la fluencia del acero vertical ubicado en la zona de tensión y por el aplastamiento de la mampostería en el extremo del muro ubicado en la zona de compresión. En el caso de mampostería confinada, el aplastamiento puede darse en el castillo, y esto suele venir acompañado por el pandeo de su acero longitudinal. La falla de un muro de mampostería confinada suele ocurrir cuando se presenta un agrietamiento horizontal excesivo, el aplastamiento del concreto en los castillos, o cuando finalmente aparecen grietas importantes a corte en el panel del muro (Meli et al.,2011).

La falla por corte suele presentarse en muros robustos de mampostería sujetos a cargas laterales (Zúñiga, 2005). En particular, la tensión diagonal inducida en el muro por las cargas laterales resulta en la 
formación de grietas diagonales que cruzan las piezas de mampostería y las juntas de mortero. Ante un incremento en la deformación lateral del muro, la grieta diagonal se extiende hasta alcanzar e invadir el concreto ubicado en la parte inferior de uno de los castillos, y el ubicado en la parte superior del otro castillo. Una vez que la grieta diagonal se extiende a los castillos, el complejo estado de esfuerzos de compresión, tensión y corte en el concreto produce la falla del muro. En general, una falla por efectos de corte se denota falla por tensión diagonal.

Las etapas iniciales de comportamiento de un muro que presenta interacción flexión/corte se ven caracterizadas por la formación de grietas horizontales en las juntas de mortero. Un incremento en la deformación lateral del muro resulta en el inicio de la fluencia del acero vertical a flexión, el aplastamiento de las piezas ubicadas en la zona de compresión, y la formación de grietas diagonales en el panel de mampostería (Shing et al., 1989; Hidalgo et al., 1978). Este comportamiento, observado en varias pruebas experimentales, resulta en una respuesta relativamente dúctil. En ocasiones la interacción flexión/corte resulta en una falla caracterizada por deslizamiento (Voon e Ingham, 2007), la cual tiende a observarse en muros que combinan bajos niveles de carga gravitacional con cargas laterales de consideración; y se caracteriza por la formación de grandes grietas horizontales a flexión en la base del muro. El deslizamiento ocurre cuando la fuerza cortante actuante excede la fuerza de fricción que el muro es capaz de desarrollar en la base. En ocasiones, es posible retrasar la ocurrencia de este tipo de falla a través de cruzar acero vertical en la superficie que desarrolla la fricción.

\section{Flexión}

En términos de la situación ideal para un muro sujeto a cargas laterales, es importante promover su trabajo a flexión. Dentro de este contexto, es necesario establecer de manera razonable su capacidad resistente a flexión y flexo-compresión, y tomar medidas para estabilizar este comportamiento en el rango plástico de respuesta.

La resistencia a flexión que tiene un muro de mampostería confinada se da a partir de la formación de un par de fuerzas. Mientras que una de ellas se da en lo esencial a partir de los esfuerzos de compresión que desarrollan la mampostería y el castillo en uno de los extremos del muro, la otra se da a partir del esfuerzo de tensión que desarrolla el refuerzo longitudinal del castillo ubicado en el otro extremo. La evidencia experimental disponible indica la pertinencia de usar la teoría convencional de flexión desarrollada para elementos estructurales de concreto reforzado para estimar la resistencia y capacidad de deformación de muros esbeltos de mampostería.

En términos de fomentar un comportamiento dúctil de un muro esbelto, es importante establecer de manera razonable su capacidad resistente a corte, de tal manera que dicha capacidad sea, conforme a lo mostrado en la figura 1, mayor que su capacidad a flexión. En la figura, $M_{p}$ es el momento plástico que el muro es capaz de desarrollar en sus extremos, $V_{R}$ su capacidad resistente a corte, y $V$ el cortante actuante en el muro. El subíndice $y$ denota fluencia.

Para establecer el diagrama de interacción momento-axial de un muro de mampostería confinada, la versión actual de las NTCDCEM-2004 usa suposiciones similares a las planteadas por las Normas Técnicas Complementarias para el Diseño y Construcción de Estructuras de Concreto (Gobierno del Distrito Federal, 2004b), NTCDCEC-2004. En particular, el método optativo de las NTCDCEM-2004 especifica que: "para muros con barras longitudinales colocadas simétricamente en sus castillos extremos, sean éstos exteriores o interiores, las fórmulas simplificadas siguientes dan valores suficientemente aproximados y conservadores del momento flexionante resistente de diseño $\left(M_{R}\right)$ : 
$M_{R}=\left\{\begin{array}{cl}F_{R} M_{0}+0.3 P_{u} d & \text { si } 0 \leq P_{u} \leq P_{R} / 3 \\ \left(1.5 F_{R} M_{0}+0.15 P_{R} d\right)\left(1-P_{u} / P_{R}\right) & \text { si } P_{u}>P_{R} / 3\end{array}\right.$

donde $M_{0}=A_{s} f_{y} d$ ' es la resistencia a flexión pura del muro; $A_{s}$ el área total de acero de refuerzo longitudinal colocada en cada uno de los castillos extremos del muro; d' la distancia entre los centroides del acero colocado en ambos extremos del muro; d la distancia entre el centroide del acero de tensión y la fibra a compresión máxima; $P_{u}$ la carga axial de diseño a compresión, cuyo valor se tomará con signo positivo; $P_{R}$ la carga vertical resistente del muro; y $F_{R}$ se tomará igual a 0.8 , si $P_{u}$ es menor o igual que $P_{R} / 3$ e igual a 0.6 en caso contrario. Para cargas axiales de tensión será válido interpolar entre la carga axial resistente a tensión pura y el momento flexionante resistente $M_{O}$, afectando el resultado por un $F_{R}=$ 0.8."

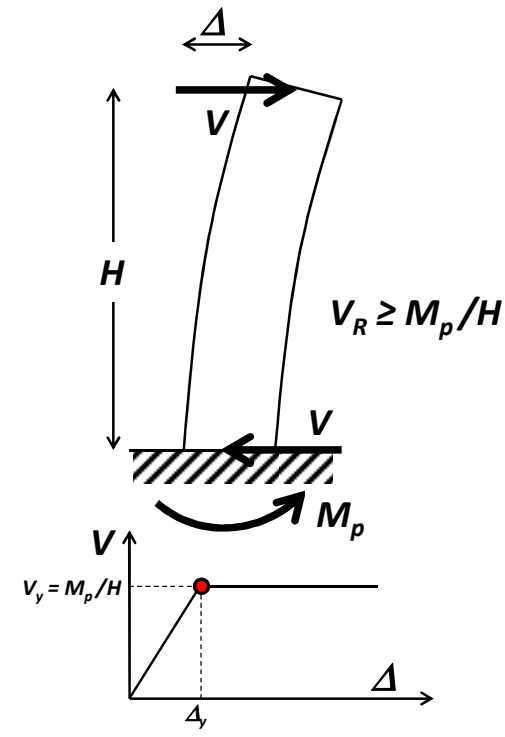

a)

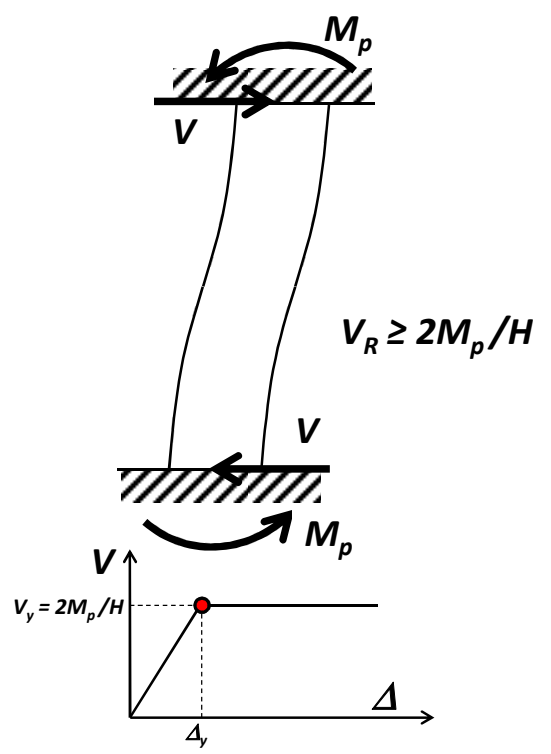

b)

Figura 1. Cortante máximo esperado en muros de mampostería que se dañan a flexión:

a) Curvatura simple; b) Doble curvatura

Tal como se ilustra en la figura 2, el nivel de conservadurismo asociado al uso del método optativo de las NTCDCEM-2004 se incrementa sustancialmente conforme se incrementa el valor de la carga axial actuante en el muro. En la figura, $f_{m}^{*}$ es la resistencia de diseño a compresión de la mampostería (referida al área bruta), y $t$ y $L$ el espesor y longitud efectiva del muro. En un contexto donde el muro debe fallar a corte, el uso del método optativo suele dar resultados del lado de la seguridad. Sin embargo, dentro de un contexto como el planteado por la figura 1, la subestimación de la capacidad a flexión del muro puede resultar en daño considerable a corte que resultaría, al final de cuentas, en un comportamiento indeseado. 


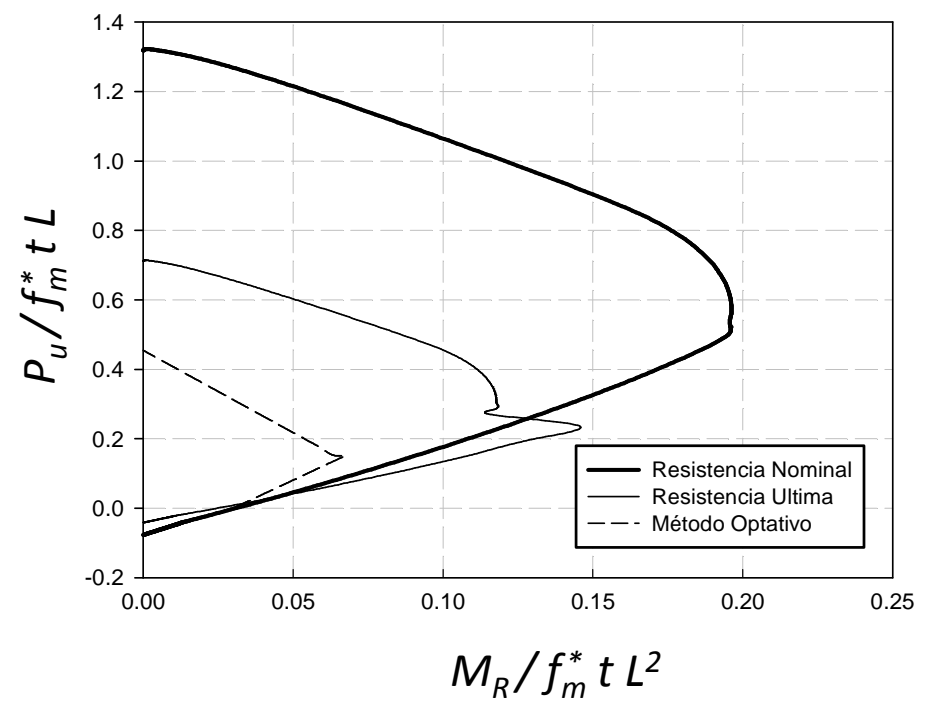

Figura 2. Diagrama de interacción calculado con diferentes métodos para un muro de mampostería

El planteamiento de un modelo de análisis para un edificio de mampostería no solo debe considerar la estimación de la resistencia de los muros, sino un entendimiento del comportamiento no lineal que desarrollan cuando se les sujeta a deformación lateral. Al respecto, las pruebas experimentales permiten obtener información que hace posible el planteamiento de modelos no lineales para representar el comportamiento de muros sujetos a la acción de cargas laterales. Entre otras cosas, se requiere lo siguiente: A) Naturaleza de las curvas de histéresis; B) Capacidad de deformación y disipación de energía; y C) Características de la degradación de resistencia y de rigidez que sufre el elemento estructural.

A partir del estudio experimental de muros de mampostería reforzada con relación de aspecto de uno, Shing et al. (1989) observaron que es posible diseñar muros para que tengan un comportamiento caracterizado por daño a flexión. De especial interés resulta el estudio experimental llevado acabo por Shedid et al. (2009) en muros de mampostería con relación de aspecto de 2. Consideraron diversas cantidades de acero tanto vertical como horizontal, y distintos niveles de carga axial. Observaron que sus muros alcanzaron a cubrir del 68 al $80 \%$ de su desplazamiento lateral total a través de su comportamiento a flexión; y que para ello desarrollaron distorsiones últimas que fueron desde el 1.6 hasta el 2.2\%. Concluyeron que la capacidad de disipación de energía de un muro depende del tipo de daño que desarrolla y, dentro de este contexto, enfatizaron la importancia de fomentar que el daño en los muros quede dominado por efectos de flexión. Un contraste entre los resultados reportados por Shing et al. (1989) y Shedid et al. (2009) permite entender que un incremento en la relación de aspecto de los muros resulta en que estos desarrollen un comportamiento a flexión con mayor capacidad de deformación y estabilidad en términos de su comportamiento histerético.

\section{Corte}

Conforme a lo mostrado en la figura 1, lograr que un muro esbelto desarrolle un comportamiento dominado por efectos de flexión implica aportarle una capacidad adecuada a corte. Desde los años setenta del Siglo XX se han llevado a cabo ensayos de muros de mampostería para obtener expresiones empíricas que sean capaces de determinar de manera razonable dicha capacidad. Estudios recientes coinciden en señalar que la resistencia a corte de un muro de mampostería queda aportada por: A) La resistencia a corte del panel de mampostería; B) La contribución de la carga axial; y C) El acero horizontal en el muro. 
Aunque en México se cuenta con una ecuación capaz de predecir de manera razonable la resistencia a corte de muros de mampostería confinada, es importante mencionar que dicha expresión aplica a muros con relación de aspecto menor o igual que la unidad, y cuya mampostería no exhibe alta resistencia. En términos de hacer posible el diseño y construcción de edificios altos de mampostería, es necesario contar con una expresión que aplique al caso de muros esbeltos de mampostería confinada de alta resistencia. Después de una amplia búsqueda de estudios llevados a cabo a nivel internacional, se encontró la propuesta de Voon e Ingham (2007) para muros de mampostería no confinada:

$V_{R}=0.8 k\left(C_{a}+C_{b}\right) A_{n} \sqrt{f_{m}^{*}}+0.9 N^{*} \tan \alpha+A_{h} f_{y h} \frac{D_{e f f}}{s_{h}} \leq 0.45 \sqrt{f_{m}^{*}}$

donde $k$, estimada en función de la demanda de ductilidad, toma en cuenta el efecto del daño a flexión en la resistencia al deslizamiento del muro (ver figura 3); $C_{a}=0.022 \rho_{v} f_{y v}$ y $C_{b}=0.083[4-1.75 M / V L]$, donde $\rho_{v}$ y $f_{y v}$ son la cuantía y esfuerzo de fluencia del acero vertical, respectivamente, y $M / V L$ la relación de aspecto; $A_{n}$ el área bruta de la sección transversal del muro; $f_{m}^{*}$ la resistencia a compresión de la mampostería; $N^{*}$ la carga axial factorizada; $\alpha$ el ángulo que se forma entre los puntos donde se supone aplicada y resistida la carga de compresión del muro; $A_{h}$ y $f_{y h}$ el área y esfuerzo de fluencia de una barra del refuerzo horizontal; $D_{\text {eff }}$ el peralte efectivo de la sección transversal; y $s_{h}$ la separación del refuerzo horizontal.
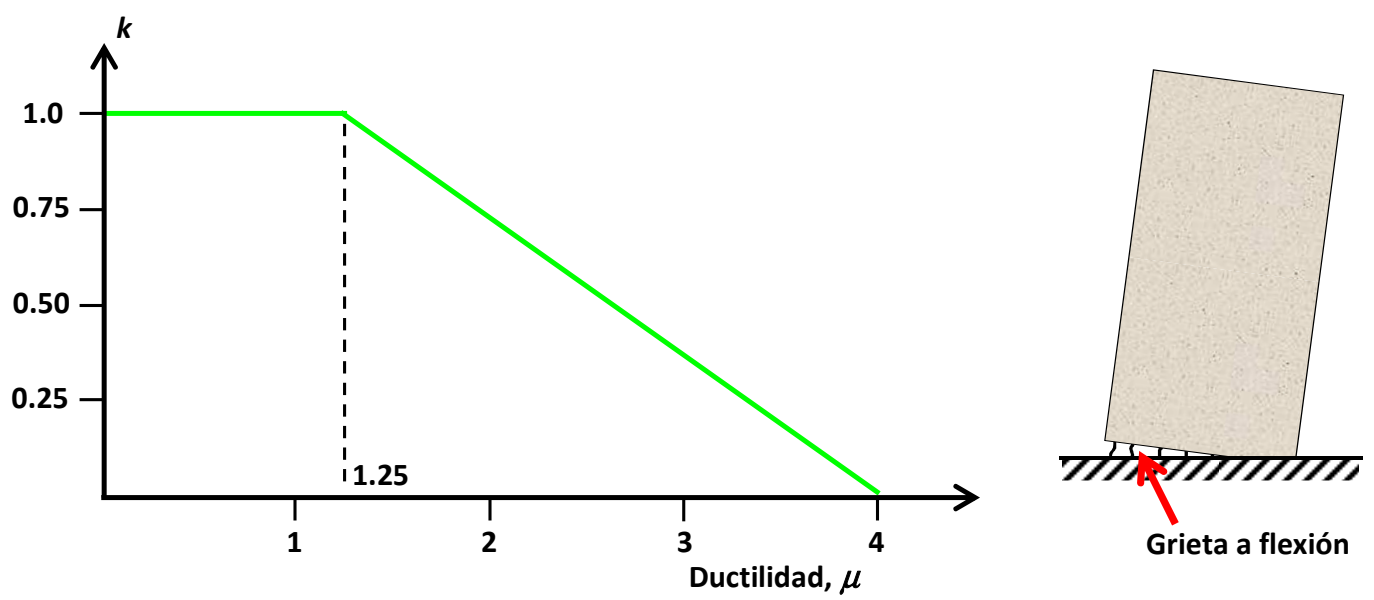

Figura 3. Efecto de daño a flexión en la resistencia a corte de un muro de mampostería (Voon e Ingham 2006)

Dado que la ecuación 1 fue desarrollada para el caso de mampostería no confinada, resulta cuestionable su aplicación al caso de muros de mampostería confinada. Mientras que por un lado, lo anterior resulta en la mayor limitación del trabajo que aquí se presenta; vale la pena mencionar, por el otro lado, que Pérez-Gavilán et al. (2013) observaron que el cortante resistente en muros esbeltos de mampostería confinada sin refuerzo horizontal no disminuye en términos relativos con un incremento en su relación de aspecto. Explican que esto se debe al mayor nivel de confinamiento provisto por los castillos en muros esbeltos. Puede decirse que es probable que la resistencia de un muro esbelto de mampostería confinada sea comparable o mayor que la que corresponde a un muro similar que no tenga castillos. En lo que sigue, se supondrá que la ecuación 1 estima de manera razonablemente conservadora la resistencia a corte de un muro de mampostería confinada fabricado con piezas de alta resistencia. Con base en ello se establece que la resistencia a corte de los muros sea suficiente para que, conforme a lo que ilustra la figura 1 , puedan alcanzar su resistencia a flexión. 


\section{ANÁLISIS NO LINEAL DE EDIFICIOS DE MAMPOSTERÍA}

El desarrollo práctico de un procedimiento de evaluación basado en desplazamientos requiere de técnicas de análisis no lineal. En particular, se requiere de un modelo no lineal capaz de reflejar la respuesta local y de entrepiso de los edificios de mampostería conforme se incrementan sus demandas de desplazamiento lateral. Dentro de este contexto, es necesario tener en cuenta que el modelo de la columna ancha representa una alternativa razonable para modelar el comportamiento elástico de muros de mampostería confinada (Pérez-Gavilán, 2012); y que los muros esbeltos de mampostería pueden ser diseñados y detallados para que su respuesta lateral quede dominada por flexión.

Un modelo que hace posible el análisis no lineal de edificios de mampostería confinada de baja altura considera que cada muro es una columna ancha modificada (Terán et al., 2009a; Terán et al., 2009b). Conforme se muestra en la figura 4a, el modelo mantiene constante la rigidez a flexión de los muros durante el análisis, y son sus propiedades a corte las que se modifican de acuerdo con el daño que sufren. El comportamiento a corte del muro (incluido su intervalo de comportamiento inelástico) se modela a través de un resorte horizontal cuyo comportamiento se establece a partir de la curva de capacidad planteada por Flores y Alcocer(1996).
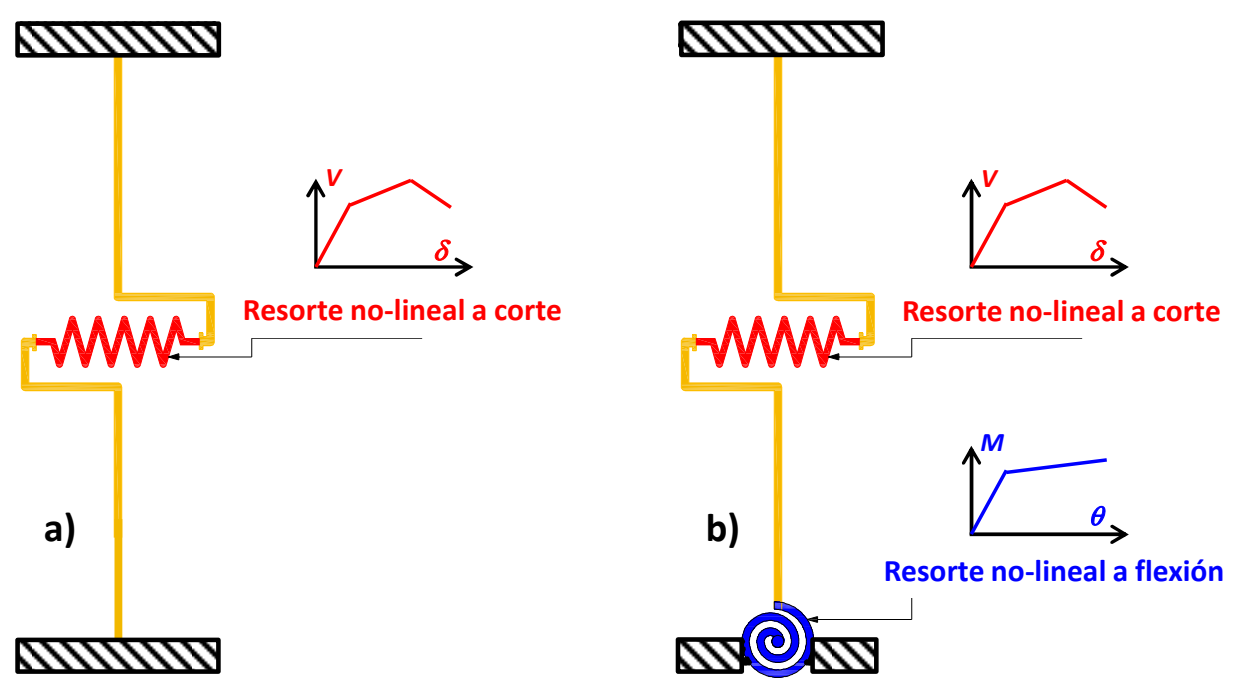

Figura 4. Modelo modificado de la columna ancha: a) comportamiento no lineal a corte; b) con interacción no lineal flexión-corte

La consideración de edificios con mayor altura implica la necesidad de modelar el comportamiento no lineal de muros cuyo daño tiende a producirse por flexión. Dada la evidencia experimental que sugiere que la teoría de flexión desarrollada para elementos de concreto reforzado es aplicable al caso de muros esbeltos de mampostería, en este trabajo se utilizó el programa XTRACT (Chadwell, 2002) para establecer, a partir de un modelo de fibras, los diagramas momento-curvatura para los muros esbeltos del edificio de 10 pisos.

Un modelo de fibras requiere de la curva esfuerzo-deformación axial de los materiales estructurales que componen el muro: la mampostería del panel, y el concreto y acero longitudinal de los castillos. En términos de curvas esfuerzo-deformación, Flores et al. (2009) establecieron modelos analíticos para mamposterías mexicanas fabricadas con: A) Ladrillo de barro rojo recocido; B) Tabicón; y C) Tabique extruido vertical de dos huecos. Dichos modelos contemplan las tres etapas planteadas por Priestley y Elder (1983) para mamposterías de alta resistencia. Aunque las pruebas desarrolladas en México para la 
mampostería de alta resistencia usada para los muros del edificio de 10 pisos solo definen la curva esfuerzo-deformación hasta el punto de resistencia máxima, es importante mencionar que la presencia de castillos en los extremos de los muros resultó en que la demanda de deformación unitaria a compresión en la mampostería no excediera la correspondiente a su resistencia máxima. En cuanto al concreto reforzado, se usó el modelo de Kent y Park (1971), capaz de tomar en cuenta el efecto benéfico que los estribos tienen en la resistencia y capacidad de deformación axial del concreto. Finalmente y en lo que se refiere al acero de refuerzo, se consideró el modelo planteado por Rodríguez y Botero (1995) con los esfuerzos resistentes que estos autores reportan para el acero mexicano.

A partir de las hipótesis básicas de la teoría de flexión para elementos esbeltos, el concepto de articulación plástica, y los diagramas momento-curvatura, es posible establecer propiedades estructurales para los muros como su rigidez a flexión, momento plástico, y sus desplazamientos de fluencia y último. Note que al imponer la condición de sección plana permanece plana, el modelo de fibras es capaz de tomar en cuenta los diferentes módulos de elasticidad del concreto y la mampostería, y contemplar su trabajo conjunto durante la estimación de las propiedades a flexión de los muros. En términos de modelado, es posible considerar explícitamente, conforme a lo mostrado en la figura 4b, el comportamiento no lineal a flexión de los muros a través de resortes plásticos ubicados en el (los) punto(s) donde se maximiza el momento flexionante.

Conforme a lo ilustrado en la figura 1, la curva de capacidad de un muro de mampostería que se daña a flexión requiere ser establecida a partir del momento plástico que el muro es capaz de desarrollar. $\mathrm{Al}$ respecto, uno de los fenómenos que más preocupan en cuanto al comportamiento no lineal de muros esbeltos de mampostería es la interacción flexión/corte, y el potencial que tiene para reducir o desestabilizar el comportamiento ante cargas laterales. En algunos casos un muro que inicio dañándose a flexión termina fallando a corte o por deslizamiento. Dentro de este contexto, una correcta caracterización de la evolución del daño en el muro requiere de un modelado adecuado de esta interacción. Vale la pena mencionar que en los análisis estáticos no lineales comentados más adelante, se estimó paso por paso la capacidad resistente a corte de los muros de acuerdo con la ecuación 2 , y se revisó que en ningún momento el cortante asociado a la formación del mecanismo a flexión excediera el valor de la resistencia a corte. Finalmente y en lo que se refiere a los análisis dinámicos no lineales, se consideró el uso de un modelo de degradación de rigidez (como el de Takeda) para modelar el comportamiento histerético de los muros esbeltos de mampostería. Dicho modelo refleja de manera adecuada la degradación de las propiedades estructurales de los muros dentro del rango contemplado en este artículo para las demandas máximas de deformación lateral.

\section{EDIFICIO DE 10 NIVELES}

Con el objetivo de mostrar la factibilidad de diseñar y construir edificios altos de mampostería en zonas sísmicas, se consideró el edificio mostrado en la figura 5. El edificio está estructurado con base en muros de mampostería confinada de alta resistencia y tiene diez pisos de 3 metros, lo que resulta una altura total de $30 \mathrm{~m}$. El edificio exhibe regularidad de masa, rigidez y resistencia lateral, tanto en planta como en altura, se destina a alojar un hotel, y se le considera ubicado en la Zona de Transición del Distrito Federal. Vale la pena mencionar que los movimientos del terreno generados en esta zona son los que inducen las mayores demandas de desplazamiento lateral en el edificio bajo consideración. Para explicar esto, es necesario mencionar que se anticipó que el periodo fundamental de vibración del edificio en su dirección crítica quedaría cercano a $1 \mathrm{seg}$; valor que corresponde al periodo dominante del terreno del sitio donde se ubica el edificio. Dada la proximidad de estos periodos, las demandas sísmicas resultantes son mayores que las que corresponderían a casos en que el edificio se ubicara en las distintas zonas epicentrales del Pacífico Mexicano o en la Zona del Lago del Distrito Federal. 


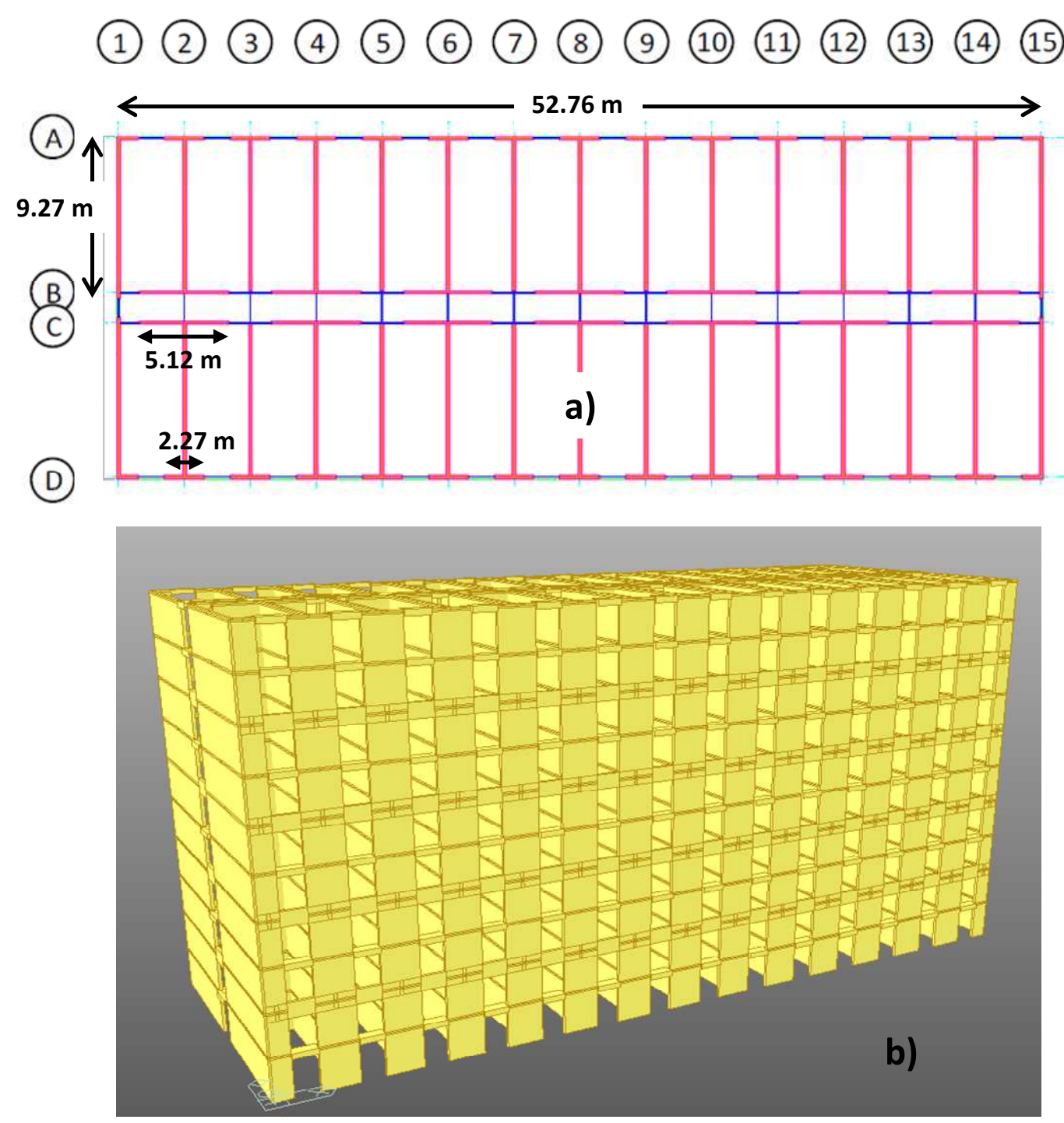

Figura 5. Configuración arquitectónica: a) Planta; b) Vista tridimensional de modelo de análisis

El edificio cuenta en la dirección corta con 15 planos formados, cada uno, por dos muros acoplados de mampostería (ejes 1 a 15). En la dirección larga existen 4 planos resistentes a sismo, 2 ubicados en las fachadas (ejes A y D) y 2 que delimitan un pasillo central (ejes B y C). En cuanto a su uso, el edificio requiere de ventanas en la fachada que permiten la entrada de luz a los cuartos, y de un pasillo central para comunicarlos entre sí. Conforme a lo mostrado, la disposición de ventanas y puertas da como resultado que en la dirección larga, los muros de pasillo tengan una longitud en planta $(5.12 \mathrm{~m})$ cercana al doble de la contemplada para los muros de fachada $(2.27 \mathrm{~m})$. Los muros de fachada en la dirección larga encuentran su comportamiento lateral fuertemente acoplado debido a la presencia de pretiles. En cuanto a los muros de pasillo, la altura de las puertas abarca la altura libre de los entrepisos, de tal manera que el comportamiento lateral de estos muros queda débilmente acoplado por las losas de entrepiso. Las características geométricas del edificio, tanto en elevación como en planta, corresponden a las de un edificio real. Por facilidad y bajo la consideración de que el trabajo reportado en este artículo constituye un estudio exploratorio, se decidió eliminar la zona de escaleras y elevadores en cada piso, y se modificó la zona de oficinas ubicada en la planta baja para que cada uno de los niveles tuviera la planta mostrada en la figura $5 \mathrm{a}$. 


\section{Diseño Estructural}

El diseño del edificio se llevó acabo conforme a los requerimientos de las NTCDCEM-2004, de las NTCDCEC-2004, y de las Normas Técnicas Complementarias para Diseño por Sismo (Gobierno del Distrito Federal, 2004c), NTCDS-2004, del Reglamento de Construcciones para el Distrito Federal. Se analizaron varias propuestas en términos de la mampostería a utilizar y el detallado de los muros. Dadas las particularidades del edificio, se requirió usar un tabique multi-perforado de alta resistencia con resistencias de diseño a compresión y cortante de $f_{m}^{*}=13.7 \mathrm{MPa}$ y $v_{m}^{*}=1.0 \mathrm{MPa}$, respectivamente. Es interesante notar que dichos esfuerzos resistentes son mucho mayores que los contemplados por las NTCDCEM-2004, y que las resistencias de diseño se establecieron en conformidad con los requisitos planteados por la normatividad local. Las dimensiones de las piezas son de $20 \times 20 \times 40 \mathrm{~cm}$, lo que resultó en muros con espesor de $20 \mathrm{~cm}$. El módulo de elasticidad de la mampostería, $E_{m}$, se consideró igual $3138.13 \mathrm{MPa}$. El sistema de piso se estructuró con base en losas macizas de concreto reforzado con espesor de $12 \mathrm{~cm}$.

Bajo la consideración de un comportamiento dominado por flexión en los muros, el análisis por sismo adoptó un factor de comportamiento sísmico $(Q)$ de 2 . Aunque en la versión inicial del edificio los muros de las fachadas orientadas en la dirección larga no cumplían con una relación de aspecto que correspondiera a la de muros esbeltos, desde el inicio del diseño se contempló la posibilidad de modificar la fachada (los detalles se discuten más adelante) para hacer posible una respuesta lateral estable a flexión. Debido a esto, no se revisaron las distorsiones de entrepiso, ya que se consideró que la distorsión máxima de entrepiso que podían alcanzar los muros de mampostería sería mayor que los límites considerados por las NTCDCEM-2004. En términos de regularidad estructural, el edificio exhibe una relación largo/ancho de la base de 2.69, la cual excede el límite reglamentario de 2.5. Debido a lo anterior, se aplicó una reducción del $10 \%$ al factor de reducción de resistencia $\left(Q^{\prime}\right)$.

La figura 6 muestra las primeras formas modales para ambas direcciones de análisis. Mientras que en la dirección larga domina un comportamiento global a corte (lo que indica que los muros trabajan como un sistema de marcos a consecuencia del fuerte acoplamiento que les proporcionan los pretiles), en la dirección corta domina un comportamiento global a flexión. El periodo fundamental de vibración $\left(T_{l}\right)$ en la dirección larga del edificio resultó estar cercano a los $0.8 \mathrm{seg}$. En términos de resistencia, a nivel global se revisaron los requerimientos de cortante basal mínimo; y a nivel local, la resistencia a flexo-compresión y corte para cada muro. A partir del análisis estructural y las expresiones normativas, se determinó que los muros fabricados con las piezas de alta resistencia son capaces de acomodar adecuadamente las demandas de carga axial, fuerza cortante y momento flexionante. Por cuestiones económicas se limitó la cuantía de acero horizontal de los muros a 0.001. En la figura 7 se resumen las dimensiones y el detallado propuesto para los diferentes castillos. La figura 8 muestra la geometría de uno de los muros centrales de fachada, y de uno de los muros de pasillo.

\section{Modificaciones al sistema estructural original}

Una vez que se tuvo disponible el diseño del sistema estructural, se hizo una inspección visual y se revisó en detalle la distribución de elementos mecánicos a lo largo, ancho y alto del edificio. Se hizo notoria una demanda excesiva de fuerza cortante en los muros ubicados en los pisos inferiores de las fachadas orientadas en la dirección larga. En términos de la dirección corta, se apreció una capacidad sismorresistente sobrada. Debido a lo anterior, se decidió solo considerar el comportamiento y desempeño sísmico del edificio en la dirección larga. 

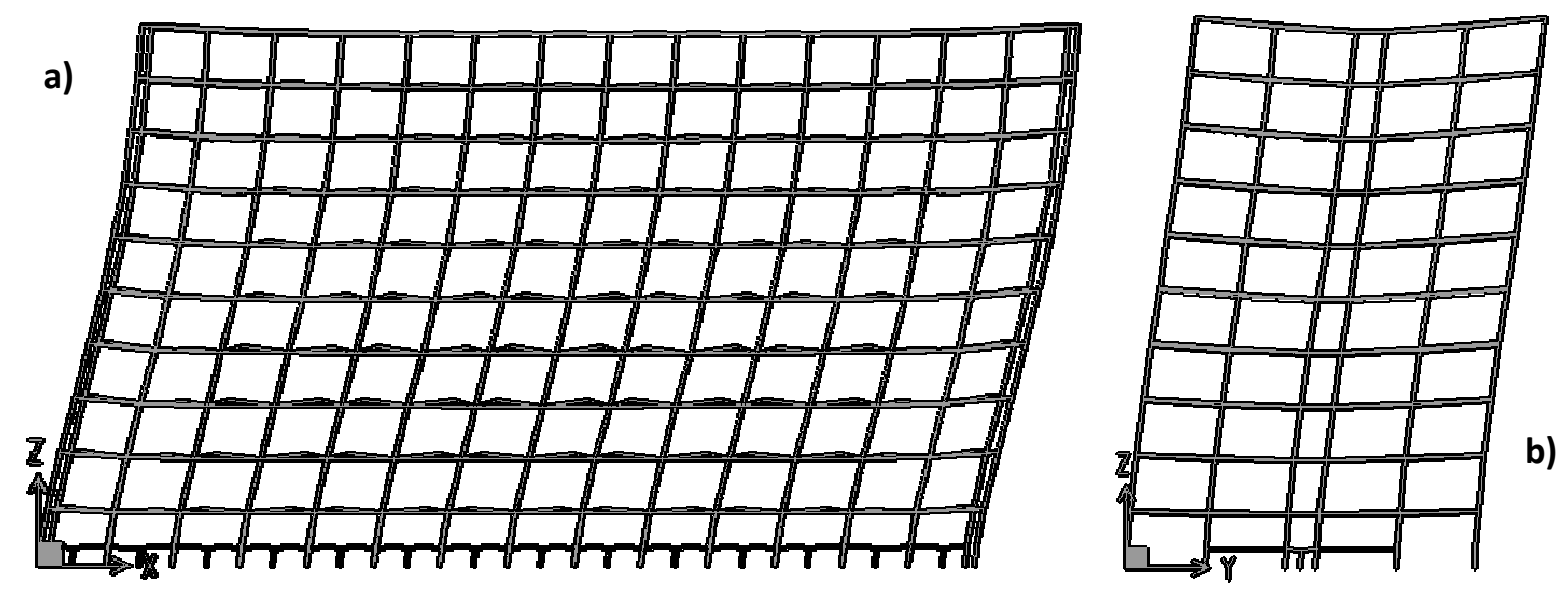

Figura 6. Configuración deformada: a) Dirección larga; b) Dirección corta

a)

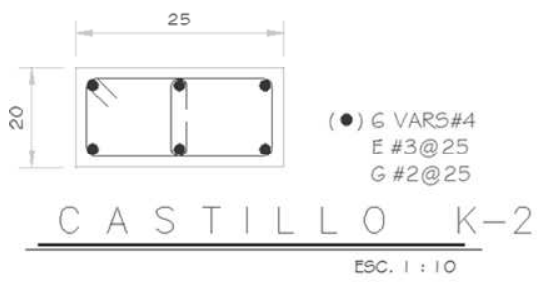

b)
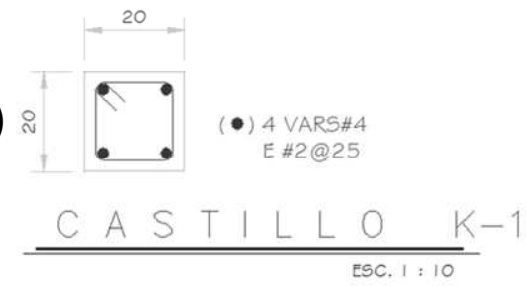

Figura 7. Armado y dimensiones de castillos de muros tipo: a) Castillo K-2; b) Castillo K-1

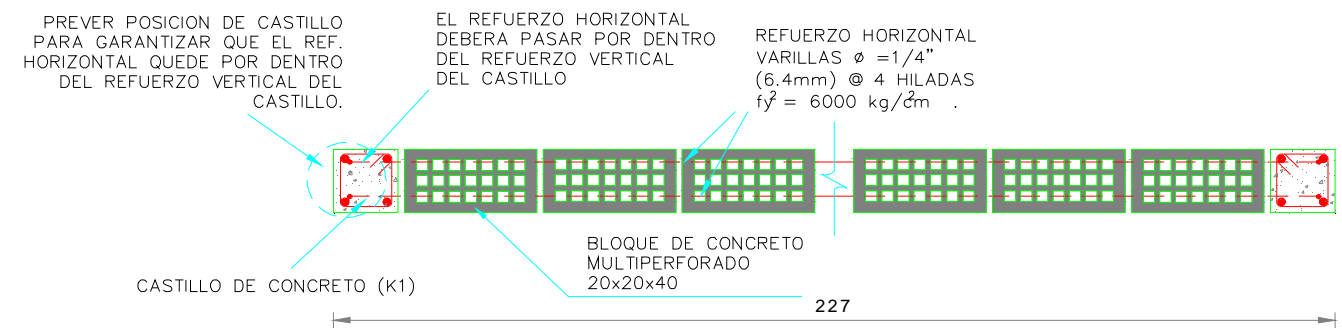

a)

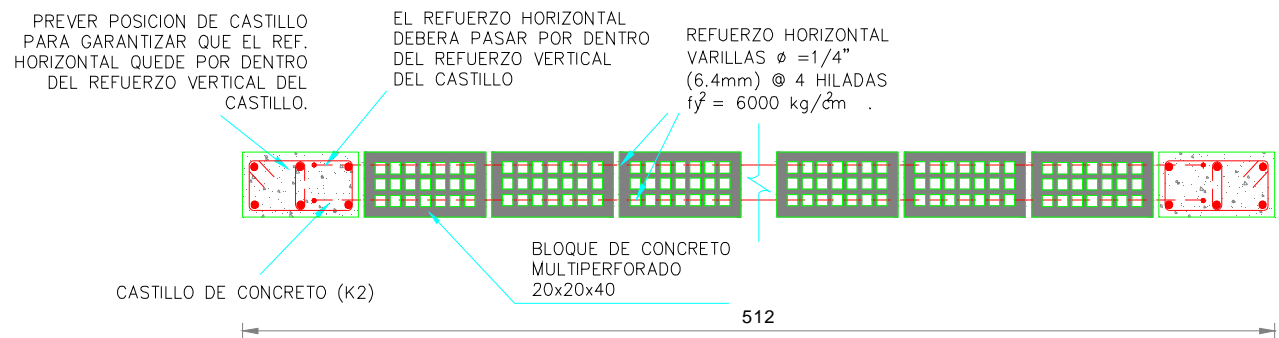

b)

Figura 8. Geometría y armado de muros en dirección larga: a) Fachada; b) Pasillo

La figura 9a ilustra como la estructuración considerada inicialmente para las fachadas en la dirección larga mostraba un alto potencial para la formación de un entrepiso débil caracterizado por la falla a corte de los muros. Dado que esto limitaba de manera considerable la capacidad de deformación 
lateral y la estabilidad de la fachada, se optó por eliminar cada dos niveles, conforme a lo mostrado esquemáticamente en la figura $9 \mathrm{~b}$, los pretiles de mampostería. Con lo anterior, se planteó para la fachada el uso de muros con un comportamiento dominado por flexión.

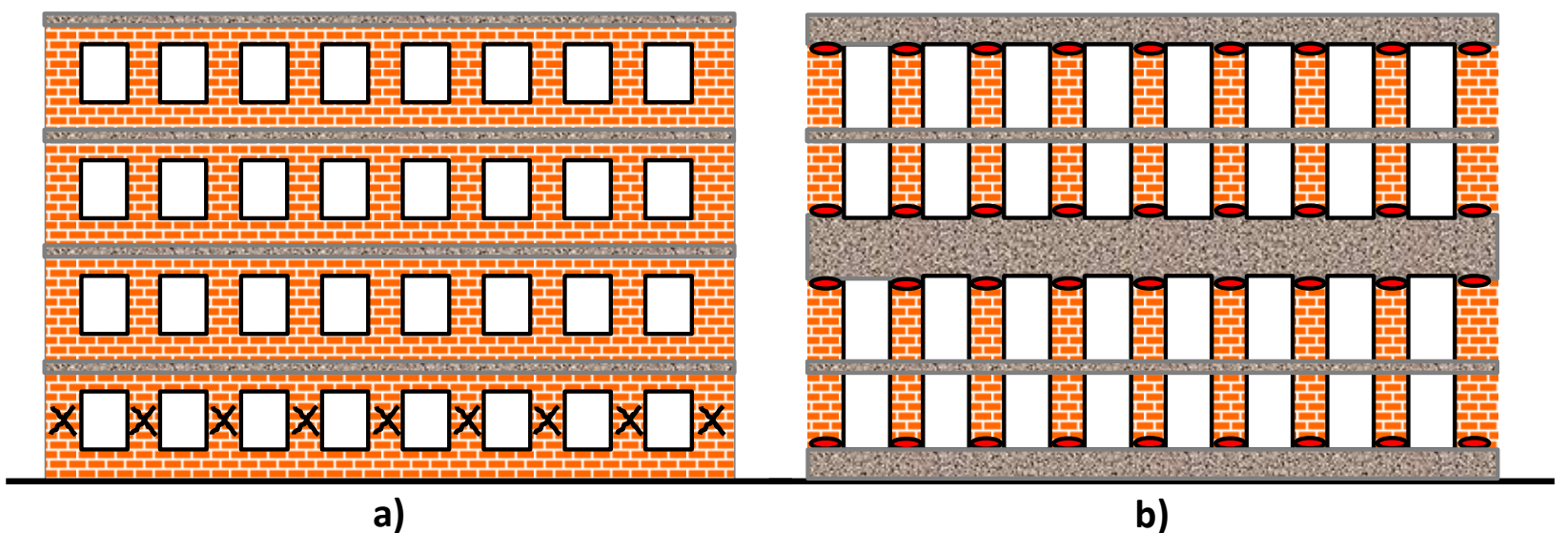

Figura 9. Estructuración de fachada en la dirección larga: a) Original; b) Definitiva

En términos de refinar el sistema estructural originalmente propuesto, hubo un segundo punto a considerar. En particular, pudo establecerse que debido a las acciones derivadas del acoplamiento que aportan a los muros, los pretiles de mampostería de la fachada tenían un alto potencial de dañarse. Aunque esto no implicaba un riesgo de colapso, no se encontró información confiable que permitiera modelar analíticamente el comportamiento no lineal de los pretiles. Debido a esto y con el fin de reducir la incertidumbre en términos del comportamiento estructural de la fachada, se propuso una alternativa que consideró el uso de pretiles de concreto reforzado. En términos de la estabilidad de los muros, y sin ser este su principal objetivo, la losa de entrepiso ubicada a la mitad de cada muro de fachada aporta apoyo que previene su posible pandeo lateral. Es importante mencionar que los pretiles de concreto fuerzan a que los muros de fachada se deformen en doble curvatura y, por tanto, a que desarrollen articulaciones plásticas en sus extremos (ver figura 9b).

En cuanto a los muros de pasillo, los espacios requeridos para las puertas de los cuartos resultan, conforme a lo ilustrado en la figura 10, en una serie de muros paralelos, esbeltos y ligeramente acoplados. Es interesante resaltar que aunque los giros en el plano de los muros de pasillo quedan ligeramente restringidos por las losas de entrepiso, la rigidez y resistencia a flexión de los primeros es mucho mayor que la de la porción de losa que los acopla, de tal manera que para efectos prácticos dichos muros exhiben un comportamiento similar al de grandes vigas en voladizo (ver figura 6b). Bajo estas circunstancias, puede considerarse que los muros exhiben una relación de aspecto cercana a 6 , y que su comportamiento queda regido por efectos de flexión. Aunque la formación de articulaciones plásticas en los muros de fachada da lugar a la formación de un mecanismo de entrepiso, las fachadas orientadas en la dirección larga están conectadas a través del sistema de piso con los muros de pasillo; los cuales aportan estabilidad lateral al sistema estructural y evitan la formación de un mecanismo global.

Inicialmente, el diseño estructural a flexo-compresión de los muros se realizó conforme al método optativo propuesto por las NTCDCEM-2004. Dado que el método optativo subestimó de manera importante la capacidad a flexo-compresión de los muros; se propuso, con el fin de evitar fallas a corte, reducir el armado longitudinal originalmente propuesto para los castillos conforme a lo resumido en la figura 11. Una opción para evitar el congestionamiento de acero longitudinal en el castillo mostrado en la figura 11b sería usar cuatro barras longitudinales $(2 \# 3+2 \# 4)$. 


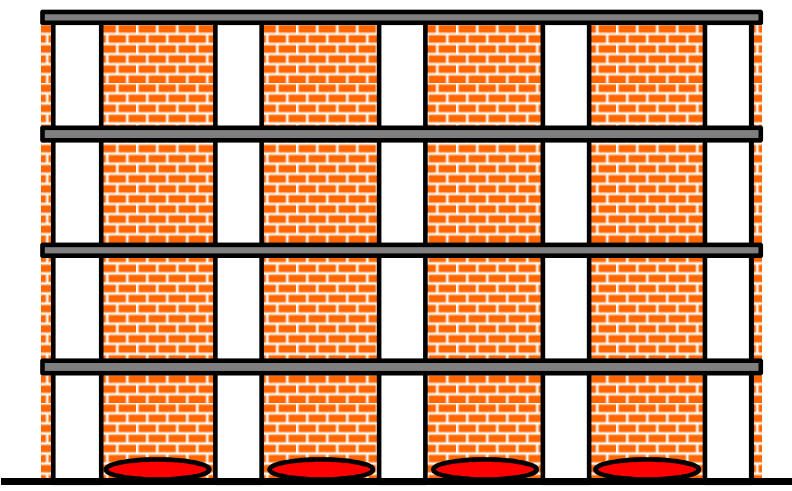

Figura 10. Estructuración de muros de pasillo en la dirección larga

a)

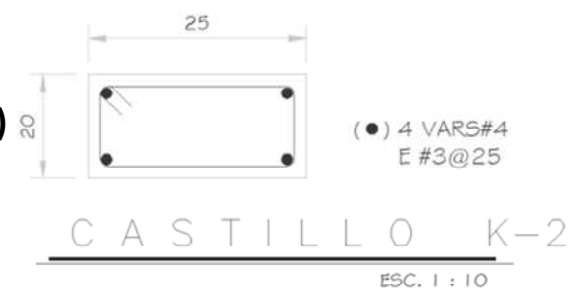

b)

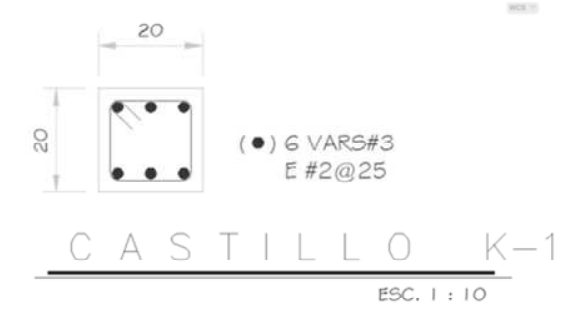

Figura 11. Armado definitivo de castillos: a) Castillo K-2; b) Castillo K-1

\section{Análisis Estático No Lineal}

Para estimar las propiedades estructurales a nivel global en la dirección larga del edificio, se preparó un modelo de análisis no lineal con el programa MIDAS GEN (2012). Se consideró un modelo de columna ancha (mostrado en la figura $4 \mathrm{~b}$ ) con plasticidad concentrada en los extremos inferior y superior de los muros. Para considerar explícitamente el comportamiento no lineal de los muros, se utilizó la teoría convencional de flexión y el concepto de articulación plástica con una longitud $\left(l_{p}\right)$ de 0.5 veces el peralte efectivo de los muros. Es importante mencionar que no se introdujo al modelo el resorte a corte bajo consideración en la figura $4 \mathrm{~b}$ debido a que para los niveles de deformación lateral contemplados en este estudio, se estableció que la resistencia a corte de los muros estimada con la ecuación 2 es suficiente para que desarrollen un comportamiento no lineal a flexión. El sistema de piso se modeló, conforme a lo requerido por el modelo de la columna ancha, como una serie de vigas equivalentes cuyas dimensiones corresponden al espesor de la losa y al ancho contemplado por las NTCDCEM-2004 (Pérez-Gavilán, 2012). Las porciones de losa que caen dentro de la longitud de los muros se modelaron como zonas infinitamente rígidas a flexión y corte. Se contemplaron apoyos empotrados para la base de los muros ubicados en la planta baja. Por tanto, no se consideraron efectos de interacción suelo-estructura durante los análisis no lineales. Al respecto, es importante mencionar que no existen estudios que permitan entender si dichos efectos tienen la posibilidad de modificar de manera importante la respuesta de un edificio ubicado en la Zona de Transición; y que dichos efectos dependen del tipo de cimentación usada para el edificio, y de la profundidad de los depósitos firmes en el sitio de interés.

En términos del periodo fundamental de vibración para la dirección larga del edificio, el programa de análisis estimó un valor de $0.78 \mathrm{seg}$. La curva de capacidad para la dirección larga del edificio se estableció a partir de un análisis estático no lineal que contempló un patrón triangular de aceleraciones en altura. La figura 12 ilustra la curva de capacidad obtenida para la dirección larga del edificio. Mientras que el eje de las abscisas considera el desplazamiento lateral de azotea $\left(\delta_{a z}\right)$, el eje de las ordenadas hace lo propio para el cortante basal $\left(V_{b}\right)$. En cuanto a la definición del desplazamiento de fluencia de azotea, el 
uso del método de la rigidez secante resulta en un desplazamiento de fluencia cercano a $7 \mathrm{~cm}$, el cual queda asociado a un cortante de fluencia cercano a $\operatorname{los} 22500 \mathrm{kN}$. El edificio es capaz de acomodar de manera estable un desplazamiento de azotea de $14 \mathrm{~cm}$, lo que corresponde a una ductilidad global de 2 . A partir de los $14 \mathrm{~cm}$, se presenta daño significativo en algunos muros de fachada y en las porciones de las losas de entrepiso que los acoplan. Dado que la losa de entrepiso no forma parte fundamental del mecanismo resistente a sismo, sería conveniente, de ser esto posible, desligarla de los extremos de los muros para incrementar su capacidad de acomodar desplazamiento lateral sin daño. La curva de capacidad muestra un comportamiento razonablemente estable hasta un desplazamiento de azotea de $20 \mathrm{~cm}$, para el cual se observa daño grave en las porciones de losa que acoplan los muros de fachada cada dos pisos (particularmente aquellas ubicadas en el primer, tercer y quinto niveles). En términos de daño en los muros, el mayor daño se observa en los muros ubicados en los extremos de la fachada, ya que desarrollan fuerzas axiales de importancia debido a su interacción con los pretiles de concreto.

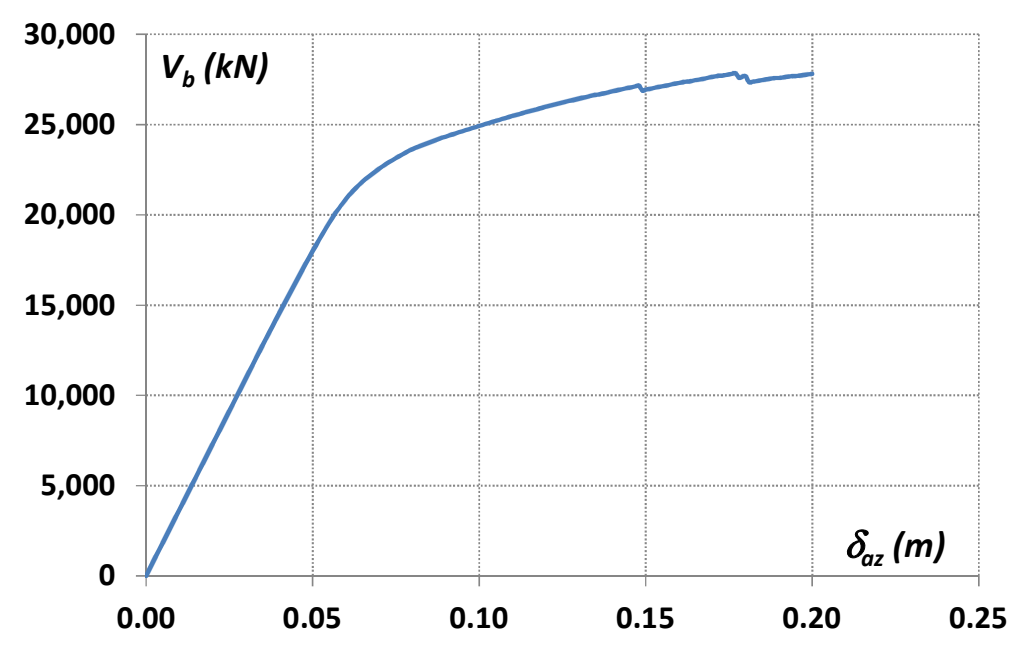

Figura 12. Curva de capacidad para la dirección larga del edificio

La figura 13 muestra la evolución en altura de la deformación lateral del edificio. Mientras que la figura 13a lo hace en términos del desplazamiento lateral de las diferentes losas $(\delta)$, la figura 13b la presenta en términos de distorsiones de entrepiso $(D E)$. La deformación lateral tiende a concentrarse en los primeros 6 pisos, tendencia que se agudiza conforme se incrementa el desplazamiento de azotea. En términos de los umbrales de desplazamiento asociados a una respuesta lateral estable, se observan demandas máximas de distorsión de 0.007 y 0.009 para desplazamientos de azotea de 15 y $20 \mathrm{~cm}$. Note que dichas distorsiones son considerablemente mayores que el límite contemplado por las NTCDCEM2004, y alrededor de la mitad de las reportadas como últimas en pruebas experimentales llevadas a cabo en muros esbeltos de mampostería no confinada. Más allá de la mayor capacidad de deformación que exhibe el edificio de 10 pisos con respecto a la esperada en una estructura de mampostería de baja altura, es importante notar que el edificio no desarrolla una planta baja débil, lo que contribuye de manera importante a su estabilidad estructural.

\section{Desempeño Sísmico de la Estructura}

Con fines de evaluar el desempeño sísmico del edificio de 10 pisos, se buscó un sitio dentro de la Zona de Transición que resultará en las mayores demandas de deformación lateral. Esto resultó en la 
consideración de un sitio con periodo dominante del terreno $\left(T_{S}\right)$ de $1 \mathrm{seg}$. Los acelerogramas bajo consideración para evaluar el desempeño sísmico del edificio se resumen en la tabla 1.
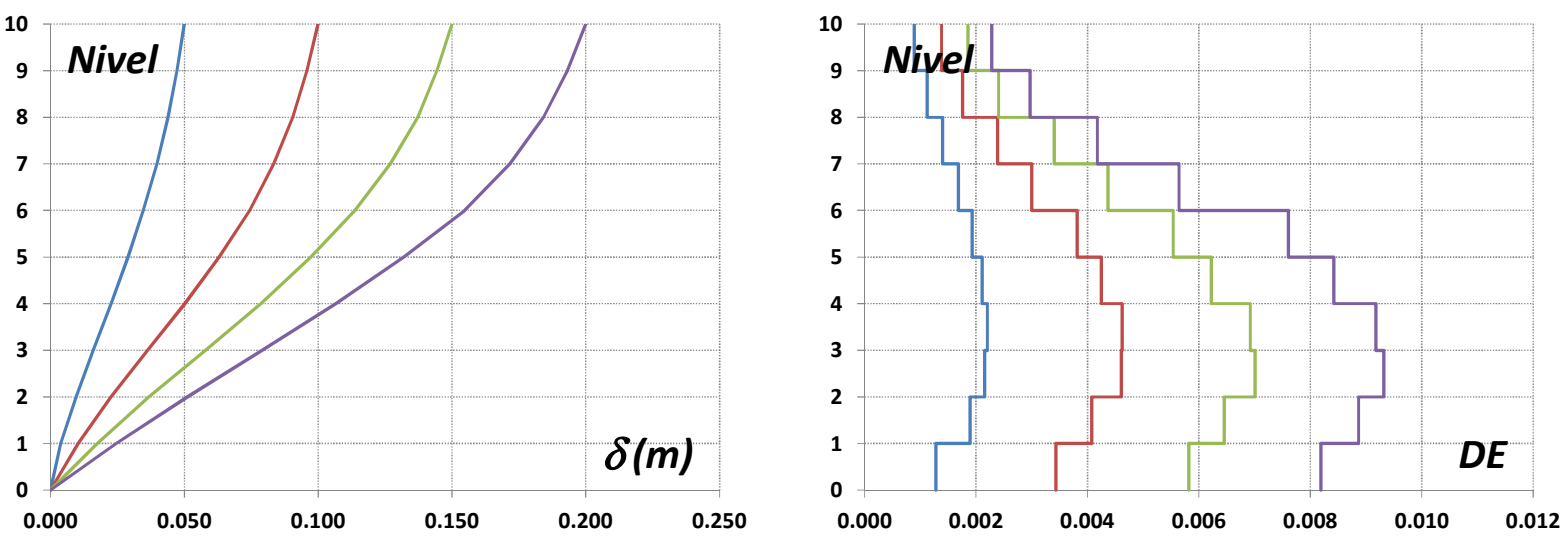

Figura 13. Evolución de la deformación lateral en altura: a) Desplazamientos de piso, b) Distorsiones de entrepiso

Todos los movimientos se escalaron linealmente de tal manera que su aceleración máxima del terreno coincidiera con el valor de $0.175 g$ prescrito por el Apéndice A de las NTCDS-2004. La figura 14 compara los espectros medio + una desviación estándar $(\sigma)$ de desplazamiento obtenidos a partir de los registros, con los espectros de diseño que, de acuerdo al Apéndice A, corresponden al sitio de la construcción. En la figura, $\mu$ denota la máxima demanda de ductilidad. Conforme a lo que puede apreciarse, el juego de movimientos ofrece, en conjunto, una caracterización numérica razonable del sismo de diseño contemplado por las normas. Es importante mencionar que como el espectro medio $+\sigma$ de los movimientos bajo consideración representan en conjunto al sismo de diseño, en adelante la respuesta media $+\sigma$ del edificio será considerada como la respuesta ante el sismo de diseño.

Tabla 1 Movimientos que caracterizan al sismo de diseño

\begin{tabular}{ccccccc}
\hline Movimiento & Estación & Evento & Componente & $\begin{array}{c}\text { Aceleración } \\
\text { Máxima del } \\
\text { Terreno } \\
\left(\mathrm{cm} / \mathrm{seg}^{2}\right)\end{array}$ & $M_{w}$ & $\begin{array}{c}\text { Factor de } \\
\text { Escala }\end{array}$ \\
\hline Acel1 & JC54 & $04 / 1989$ & EO & 29.96 & 6.9 & 5.730 \\
Acel2 & JC54 & $04 / 1989$ & NS & 28.18 & & 6.092 \\
Acel3 & JC54 & $06 / 1999$ & EO & 35.53 & 5.8 & 4.832 \\
Acel4 & JC54 & $06 / 1999$ & NS & 43.69 & & 3.930 \\
Acel5 & DX37 & $04 / 1989$ & EO & 33.78 & 6.9 & 5.083 \\
Acel6 & DX37 & $04 / 1989$ & NS & 31.28 & & 5.488 \\
Acel7 & DX37 & $09 / 1999$ & EO & 26.81 & 7.5 & 6.404 \\
Acel8 & DX37 & $09 / 1999$ & NS & 23.51 & 6.302 \\
Acel9 & ME52 & $04 / 1989$ & NS & 20.85 & 6.9 & 8.233 \\
Acel10 & ME52 & $09 / 1995$ & EO & 27.37 & 6.4 & 6.273 \\
Acel11 & ME52 & $09 / 1995$ & NS & 21.33 & 7.5 & 8.163 \\
Acel12 & ME52 & $09 / 1999$ & NS & 21.03 & 7.5 \\
\hline
\end{tabular}



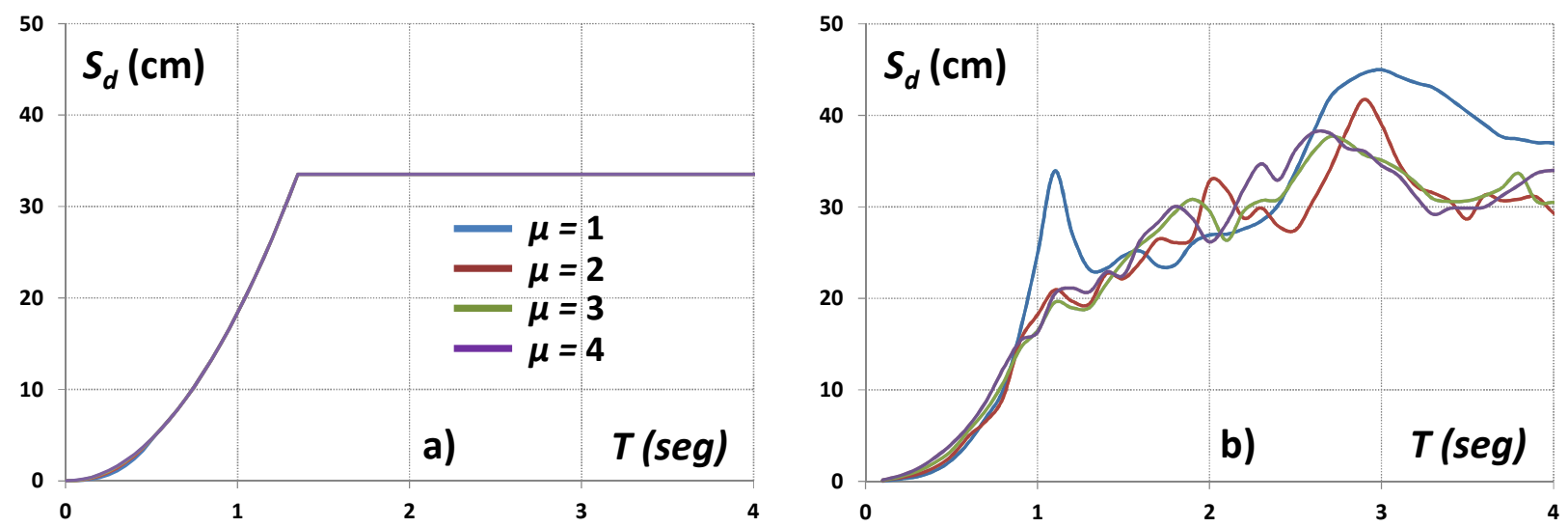

Figura 14 Comparación de espectros de desplazamientos: a) Normativos; b) Media $+\boldsymbol{\sigma}$

El desempeño sísmico del edificio se estableció a partir de una serie de análisis dinámicos no lineales. La figura 15 muestra con líneas rojas las deformaciones laterales que los diferentes movimientos del terreno demandan del edificio, y con línea negra la media $+\sigma$ de dichas demandas. La demanda media $+\sigma$ de desplazamiento de azotea está cercana a los $15 \mathrm{~cm}$, valor que puede ser alcanzado por el edificio de manera estable. En términos del nivel de daño estructural y conforme a lo mencionado antes, esto corresponde a daño severo en unos cuantos muros de fachada y las porciones de losa que los acoplan; y daño entre leve y moderado en la base de los muros ubicados en los pasillos. La demanda media $+\sigma$ de distorsión exhibe un valor cercano a 0.007 , valor que excede por mucho el límite de 0.0025 especificado por las NTCDCEM-2004.
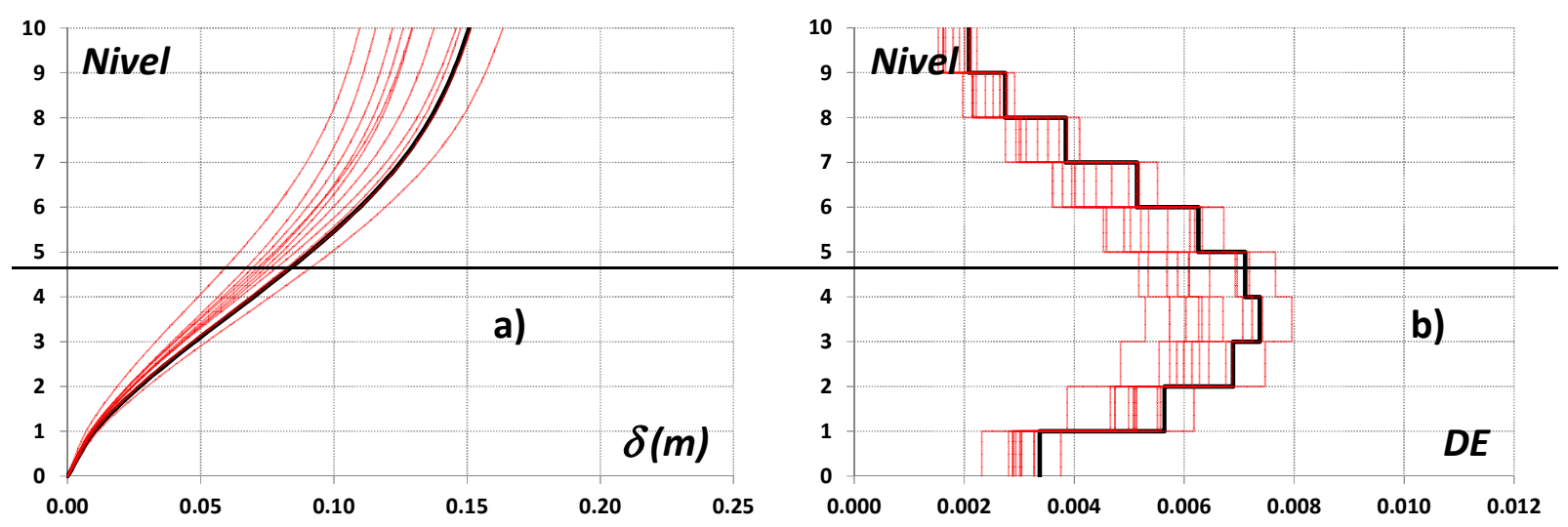

Figura 15 Demanda de deformación lateral: a) Desplazamiento de piso;

b) Distorsiones de entrepiso

\section{DISCUSIÓN}

El comportamiento global del edificio en la dirección larga puede entenderse a partir de considerar que por un lado y dado que estas se dañan a deformaciones menores, las fachadas se constituyen en un fusible estructural capaz de disipar una cantidad importante de energía. Por el otro lado, los pasillos aportan un núcleo estructural que exhibe un comportamiento dúctil y estable. El edificio de mampostería tiene en su dirección larga la capacidad de acomodar de manera confiable deformaciones laterales mayores que la asociada a la pérdida de la capacidad resistente de la fachada. 
Existen varias preocupaciones que han sido expresadas alrededor de la posibilidad de construir edificios altos de mampostería en zonas sísmicas. Por un lado puede hablarse del efecto de junta, que consiste en la falla por tensión que se observa en la pieza de mampostería ubicada en la zona de máxima compresión axial de muros de mampostería no confinada que se dañan a flexión. Conforme a lo discutido por Espinosa (2013), este efecto se debe a los diferentes módulos de elasticidad que exhiben las piezas de mampostería y el mortero. Aunque en muros de mampostería confinada la inestabilidad prematura debido al efecto de junta no se ha manifestado de manera sistemática, es posible que este mecanismo pueda llegar a presentarse en presencia de deformaciones unitarias a compresión excesivas. Al respecto, es importante notar que en el caso de mampostería confinada, las máximas deformaciones se desarrollan en los castillos extremos, de tal manera que un dimensionado y detallado adecuado de estos resultan en una reducción importante de las deformaciones unitarias en la mampostería y, por tanto, en el retraso o desaparición del efecto de junta.

Dado que uno de los castillos debe estabilizar la parte del muro que desarrolla compresión, existe también preocupación del posible aplastamiento del concreto o del pandeo del refuerzo longitudinal. Al respecto y tal como sucedería con un elemento de borde de un muro de concreto reforzado, un detallado adecuado de los estribos resultaría en una respuesta estable a flexión. Otro tipo de falla observada en muros de mampostería confinada se da cuando bajo el efecto de un momento flexionante, los castillos se separan del panel de mampostería. Aunque sería necesario estudiar experimentalmente las medidas requeridas para evitar esta separación, es posible decir que una de ellas sería el detallado del refuerzo horizontal a corte de tal manera que amarre el castillo al panel de mampostería.

Otro tema que llama la atención es la posibilidad de que los muros de mampostería desarrollen cargas axiales de importancia. Vale la pena mencionar que en el edificio de 10 pisos, la gran mayoría de los muros de fachada solo soportan cargas axiales producidas por las cargas gravitacionales, aun cuando se deforman lateralmente por efecto de sismo. Note que las cargas axiales inducidas por sismo en un muro se deben a los cortantes que desarrollan los elementos horizontales. Mientras que en un muro interno los cortantes que desarrollan los elementos horizontales se cancelan entre sí, los muros externos se ven sujetos a incrementos importantes en sus niveles de carga axial. Al respecto, el daño que puedan sufrir los muros externos en la dirección larga tiene un impacto mínimo en la capacidad global resistente a sismo de la fachada. Más allá del ejemplo específico desarrollado en este artículo, debe reconocerse que en algunos casos la carga gravitacional acumulada en varios pisos puede resultar en una reducción significativa de la capacidad de deformación lateral de los muros.

Ha sido común en México que el sistema estructural de los edificios se resuelva con base en el uso de marcos rígidos de concreto reforzado. En términos generales, el ingeniero estructural mexicano considera que el desempeño sísmico de este tipo de sistema estructural será satisfactorio cuando se cumplan con los requerimientos de diseño que marca el Reglamento de Construcciones para el Distrito Federal. Con base en lo anterior, es muy probable que el edificio de 10 pisos hubiese sido resuelto con base en marcos rígidos de concreto reforzado. Para establecer una base de comparación, se diseñó una nueva versión para el sistema estructural del edificio de 10 pisos. En particular se consideró el uso de marcos rígidos de concreto reforzado con detallado estándar. Las condiciones de diseño fueron muy similares a las planteadas para el edificio de mampostería (Espinosa Cazarín et al., 2013). En términos de su capacidad resistente, ambas versiones del edificio fueron capaces de alcanzar un coeficiente sísmico cercano a 0.7. En términos de rigidez lateral, la estructura de mampostería exhibe un valor que es $20 \%$ mayor con respecto al correspondiente al del edificio de concreto reforzado. La capacidad de deformación máxima aceptable para los edificios de mampostería y concreto reforzado es de 20 y $25 \mathrm{~cm}$, respectivamente. En cuanto a las demandas media $+\sigma$, se estimaron demandas de desplazamiento de azotea de 15 y $18 \mathrm{~cm}$, respectivamente. Esto conlleva demandas máximas de distorsión de entrepiso cercanas a 0.008 y 0.010 , respectivamente. Bajo la consideración de un balance demanda-capacidad, el 
rediseño del edificio con concreto reforzado resultó en una estructura con $20 \%$ mayor capacidad de deformación que se deforma $20 \%$ más durante el sismo de diseño. Ambas versiones del edificio son capaces de acomodar adecuadamente las demandas sísmicas y, en lo global, exhiben un desempeño sísmico similar. El peso de ambos sistemas estructurales (sin contemplar el peso de los sistemas de piso, elementos no estructurales y cargas vivas del edificio) es prácticamente igual $(35,500 \mathrm{kN})$.

Es posible observar una alta densidad de muros paralelos a la dirección corta del edificio. Enfocando la evaluación del desempeño sísmico en esta dirección desde una perspectiva basada en desplazamientos, es posible decir, en términos generales, que para que la dirección corta tuviera demandas de desplazamiento similares a las de la dirección larga, habría que eliminar 10 de los 30 muros orientados en esta dirección. Dada la necesidad de separar los espacios de los cuartos, esto implicaría sustituir los muros estructurales de mampostería por muros divisorios, y detallar dichos muros para que pudieran acomodar las deformaciones laterales del edificio.

Un tema que no se consideró explícitamente en los estudios reportados aquí es la estabilidad fuera del plano de los muros de mampostería. Aunque esto no ha sido un problema en el pasado, sería necesario considerar que las aceleraciones de entrepiso crecen conforme se incrementa la altura del mismo. Solo recientemente se han hecho esfuerzos por entender y modelar el comportamiento fuera del plano de muros de mampostería confinada (Varela et al., 2011; Varela et al., 2012), y los resultados experimentales sugieren que este tipo de muros posee una elevada resistencia fuera del plano.

Finalmente, es importante mencionar que la mampostería resulta de combinar una serie de materiales que por separado tiene características mecánicas propias, y cuya compleja interacción da lugar a propiedades estructurales emergentes que resultan atractivas desde un punto de vista estructural. Por tanto, las acciones discutidas en este artículo para hacer posible el diseño y construcción de edificios altos de mampostería deben ser complementadas con medidas de control que resulten en mamposterías de alta resistencia con calidad adecuada y uniforme.

\section{CONCLUSIONES}

Los ensayos experimentales llevados a cabo a nivel internacional indican que el comportamiento de muros esbeltos de mampostería puede llegar a ser dúctil, y tener asociado altas capacidades de deformación lateral y disipación de energía. La construcción de edificios de mampostería de gran altura será posible en la medida que se desarrollen en México mamposterías de alta resistencia y se planteen sistemas estructurales que promuevan el comportamiento a flexión de los muros. Dentro de este contexto, la normativa actual debe modificar y/o esclarecer las hipótesis con que se analizan y diseñan las estructuras de mampostería. De particular importancia para el diseño de edificios altos de mampostería resultan la revisión de los requerimientos normativos relativos a las distorsiones de entrepiso, y el conservadurismo implícito en el uso del método optativo para la determinación del diagrama de interacción flexión-carga axial de un muro de mampostería.

Los resultados obtenidos a partir del modelado no lineal de un edificio de 10 pisos, y de la evaluación de su desempeño estructural, sugieren que los muros contemplados para el edificio no tendrán problemas en términos de su resistencia a corte. Al respecto, es importante mencionar que dicha resistencia fue evaluada a partir de una expresión establecida a nivel internacional, la cual debe ser avalada o corregida a la brevedad para su uso dentro del contexto de la práctica mexicana.

La presencia de castillos estabilizó la respuesta a flexión de los muros bajo consideración en este artículo, y eliminó la posibilidad de aplastamiento de la mampostería. El modelado de los muros a través 
de un modelo de fibras permitió entender que el bajo contenido de acero de los castillos resultó en profundidades pequeñas para el eje neutro del lado de la zona de compresión del muro, lo que a su vez resultó en que las deformaciones unitarias en las piezas de mampostería vecinas al castillo sujeto a compresión resultarán prácticamente nulas. Aunque en estudios experimentales se ha llegado a observar el aplastamiento de las piezas de mampostería en la zona de compresión; puede decirse, a partir de los resultados presentados en este artículo, que un diseño adecuado de los castillos hace posible una respuesta estable a flexión de muros confinados de mampostería de alta resistencia.

Aunque durante su respuesta ante sismo, el edificio de 10 pisos llega a exhibir daño severo en los muros extremos de fachada, la estabilidad global queda garantizada por un núcleo estructural formado por los muros de pasillo, los cuales son capaces de aportar una resistencia a sismo adecuada aún para elevadas demandas de desplazamiento de azotea. Es importante hacer notar que los cambios sugeridos al sistema estructural originalmente planteado resultaron en un edificio con mayor capacidad de deformación lateral y que no desarrolla una planta baja débil una vez que ingresa a su rango plástico de comportamiento.

Más allá de las consideraciones hechas en este trabajo para hacer posible el diseño de edificios altos de mampostería en zonas sísmicas, es relevante destacar la importancia de un control de calidad adecuado en términos de los materiales estructurales, y del detallado proporcionado en campo a los muros. Además de lo anterior, es importante llevar a cabo una serie de estudios experimentales capaces de desarrollar expresiones de diseño para muros esbeltos de mampostería fabricados con mamposterías mexicanas de alta resistencia. Dichos estudios deberán considerar la obtención de curvas esfuerzo-deformación axial que contemplen el comportamiento de la mampostería hasta la falla.

\section{AGRADECIMIENTOS}

El trabajo aquí reportado forma parte de las actividades del Comité de Mampostería de la Sociedad Mexicana de Ingeniería Estructural y de la Red interinstitucional para el Desarrollo e Innovación en Ingeniería Estructural. Los autores desean agradecer los apoyos financieros otorgados por el Consejo Nacional de Ciencia y Tecnología (CONACyT) y la Comisión Nacional de la Vivienda (CONAVI) a través de su Fondo de Desarrollo Científico y Tecnológico para el Fomento de la Producción y Financiamiento de Vivienda y el Crecimiento del Sector Habitacional, y por el Programa de Mejoramiento del Profesorado (PROMEP) de la Secretaría de Educación Pública.

\section{REFERENCIAS}

Chadwell, C B (2002), "XTRACT V. 3.0.9 cross section analysis software for structural and earthquake engineering," Imbsen y Associates.

Espinosa, E (2005), "Diseño sismoresistente de edificios altos de mampostería," Tesis de Maestría, Universidad Nacional Autónoma de México.

Espinosa Cazarín E F, A Terán Gilmore O Zuñiga Cuevas y R Jean (2013), “Análisis comparativo de la respuesta sísmica de dos edificios de 10 niveles: mampostería confinada versus concreto reforzado," XIX Congreso Nacional de Ingeniería Sísmica, Veracruz, Veracruz.

Flores, A, D Arroyo y L Quiroz (2009), "Modelos esfuerzo deformación axial para mampostería confinada fabricada en México D.F.", Memorias del XVII Congreso Nacional de Ingeniería Sísmica, Puebla, Puebla. 
Flores, L y S M Alcocer (1996), "Calculated response of confined masonry structures," Eleventh World Conference on Earthquake Engineering, Artículo No. 1830, Acapulco, Guerrero.

Gobierno del Distrito Federal (2004a), "Normas Técnicas Complementarias para el Diseño y Construcción de Estructuras de Concreto", Gaceta Oficial del Gobierno del D.F., TOMO I, No. 103-BIS, pp. 88194.

Gobierno del Distrito Federal (2004b), "Normas Técnicas Complementarias Para el Diseño y Construcción de Estructuras de Mampostería", Gaceta Oficial del Gobierno del D.F., TOMO I, No. 103-BIS, pp. 4-53.

Gobierno del Distrito Federal (2004c), "Normas Técnicas Complemetarias para Diseño por Sismo", Gaceta Oficial del Gobierno del D.F., TOMO II, No. 103-BIS, pp. 55-77.

Hidalgo, P, R Mayes, H McNiven y R Clough (1978), "Cyclic loading tests of masonry single piers,Volume 1 -height to width ratio of 2", Reporte UCB/EERC-78/27, Earhquake Engineering Research Center, Universidad de California en Berkeley.

Kent, D C y R Park (1971), "Flexural members with confined concrete," Journal of Structural Engineering, vol. 97, pp. 1969-1990.

Meli, R, S Brzev, M Astroza, T Boen, F Crisafulli, J Dai, M Farsi, T Hart, A Mebarki, I Moghadam, D Quiun, M Tomazevic y L Yamin (2011), "Seismic design guide for low-rise confined masonry buildings,"World Housing Encyclopedia, Earthquake Engineering Research Institute.

MIDAS GEN (2012), "Integrated design system for buildings and general structures", MIDAS Information Technology.

Pérez-Gavilán JJ (editor) (2012), "Guía de análisis de estructuras de mampostería”, Sociedad Mexicana de Ingeniería Estructural, Comité de Mampostería.

Pérez-Gavilan, J J, S M Alcocer y L E Flores (2013), "Efecto de la esbeltez en la resistencia de muros de mampostería confinada,"Revista de Ingenieria Sismica, vol. 89, pp. 55-76.

Priestley, M J N y D M Elder (1982), "Seismic behavior of slender concrete masonry shear walls,"Research Reportvol. 82 (4), Departament of Civil Engineering, University of Canterbury.

Priestley, M J N y D M Elder (1983), "Stress-strain curves for unconfined and confined concrete masonry,"ACI Journal Proceedings, vol. 8 (3), pp. 192-201.

Rodriguez, M y J C Botero (1995), "Comportamiento sísmico de estructuras considerando propiedades mécanicas de aceros de refuerzo mexicanos,"Revista de Ingeniería Sismica, vol. 49, pp. 39-50.

Shedid, M T, W W El-Dakhakhni y R G Drysdale (2009), "Behavior of fully grouted reinforced concrete masonry shear walls failing in flexure: analysis,"Engineering Structures, vol. 31(9), pp. 2032-2044.

Shing, P, J Noland, E Klamerus y H Spaeh (1989), "Inelastic behavior of concrete masonry shear walls,"Journal of Structural Engineering, vol. 115(9), pp. 2204-2225.

Terán-Gilmore, A, D Arroyo y J Ruiz (2009a), "Diseño por desempeño ¿el futuro para el diseño de las estructuras de mampostería?,"VI Simposio Nacional Sobre Ingeniería Estructural en la Vivienda, Guanajuato, Guanajuato.

Terán-Gilmore A, O Zúñiga-Cuevas y J Ruiz-García (2009b), "Displacement-based seismic assessment of low-height confined masonry buildings", Earthquake Spectra, vol. 25(2), no. 439-464.

Terán Gilmore, A, O González Cuevas, O Zúñiga y R Jean (2011), "Efecto de un piso transfer en el desempeño sísmico de una edificación de mampostería confinada," Reporte UAM-A/DMAE2011/02, Universidad Autónoma Metropolitana. 
Voon, K y J Ingham (2006), "Experimental in-plane shear strength investigation of reinforced concrete masonry walls,"Journal of Structural Engineering, vol. 132(3), pp. 400-408.

Voon, K y J Ingham (2007), "Design expression for the in-plane shear strength of reinforced concrete masonry,"Journal of Structural Engineering, vol. 133(5), pp. 706-713.

Valenzuela, E (2009), "Sobrerresistencia en estructuras de mamposteria," Tesis de Maestría, Universidad Autónoma Metropolitana.

Varela-Rivera J, D Navarrete-Macias, LE Fernandez-Baqueiro, EI Moreno (2011), "Out-of-plane behaviour of confined masonry walls,"Engineering Structures, vol. 33, pp.1734-1741.

Varela-Rivera J, M Polanco-May, L Fernandez-Baqueiro y EI Moreno (2012), "Confined masonry walls subjected to combined axial loads and out-of-plane uniform pressures," Canadian. Journal of Civil Engineering, vol. 39, pp. 439-447.

Zúñiga, O (2005). "Evaluación analítica de la respuesta sísmica de las edificaciones de mampostería," Tesis de Maestría, Universidad Autónoma Metropolitana. 